\title{
Are mass-market digital strategies an oxymoron in the luxury fashion industry? An insight from China
}

\author{
Document Version \\ Accepted author manuscript
}

Link to publication record in Manchester Research Explorer

\section{Citation for published version (APA):}

Liu, S., \& Henninger, C. E. (Accepted/In press). Are mass-market digital strategies an oxymoron in the luxury fashion industry? An insight from China. In Fashion in China in the 21st century: from design to branding Springer Nature.

\section{Published in:}

Fashion in China in the 21st century

\section{Citing this paper}

Please note that where the full-text provided on Manchester Research Explorer is the Author Accepted Manuscript or Proof version this may differ from the final Published version. If citing, it is advised that you check and use the publisher's definitive version.

\section{General rights}

Copyright and moral rights for the publications made accessible in the Research Explorer are retained by the authors and/or other copyright owners and it is a condition of accessing publications that users recognise and abide by the legal requirements associated with these rights.

\section{Takedown policy}

If you believe that this document breaches copyright please refer to the University of Manchester's Takedown Procedures [http://man.ac.uk/04Y6Bo] or contact uml.scholarlycommunications@manchester.ac.uk providing relevant details, so we can investigate your claim.

\section{OPEN ACCESS}


Are mass-market digital strategies an oxymoron in the luxury fashion industry? An insight from China

Dr Sindy Liu

Dr Claudia E Henninger, Claudia.Henninger@manchester.ac.uk, Department of Materials, University of Manchester, Sackville Street Building, Manchester, M13 9FL

\section{Abstract}

The chapter aims to provide an overview of whether mass-market digital marketing strategies are an oxymoron in the luxury fashion industry by focusing on China as a case study. The authors carefully review current market reports, media articles, and academic publications in order to shed light on who the current Chinese luxury fashion consumers are, how they are characterised, what their digital preferences are and how they engage with luxury fashion purchases. It provides an insight into key communication platforms used in China, how and why they have developed and in how far they differ to Western platforms. The chapter concludes by highlighting what is currently known in the industry, yet under-researched in the field of academia, and thus, provides avenues of future research.

\section{Introduction}

In 1987 the band R.E.M. highlighted 'it is the end of the world as we know it...', which holds truer than ever in the $21^{\text {st }}$ century. We have seen a digital ( $r$ )evolution that has changed the way businesses operate (McCormick et al., 2014). We have seen a shift from solely focusing on bricks and mortar stores to developing an omni-channel (cross-channel) strategy designed to enhance the user experience (Blazquez, 2014; Kent et al., 2016). To explain, consumers are increasingly getting used to the $24 / 7$ access of information, as well as being able to make purchase decisions, quite literally, wherever they want - on the beach, at work, or in their own home. In order to accommodate this increased flexibility companies need to invest in their mobile apps, websites, bricks and mortar stores, and their other outlets/platforms in order to ensure that the transitions between them, as well as the overall user experience (interaction) is seamless and similar in nature (Blazquez, 2014; Kent et al., 2016). Past research has emphasised that a positive user experience, especially in the online/digital context, is vital in order to enhance customer satisfaction and brand loyalty, both of which are vital for any fashion company, seeing as the industry is extremely volatile (Morgan-Thomas \& Veloutsou, 2013; Lee et al., 2015; Deloitte, 2019). As such, it may not come as a surprise that especially luxury fashion organisations have more recently increased their investments into their social media platforms and, more generally, their digital marketing strategies and channels, thereby building a stronger presence on electronic (e-), mobile (m-) and social-commerce (s-commerce) platforms (Lin et al., 2017; Bürklin et al., 2019; Deloitte, 2019). The ultimate goal is to create long-lasting consumer relationships and enhance brand loyalty, which can be challenging at times as there is an increased choice available in the luxury fashion market (Bu et al., 2017; Liu et al., 2019). Although past research focusing on social media marketing and more specifically on social media, is manifold, there are only limited studies available that provide an insight into luxury fashion organisations' strategies within the Chinese market segment (Liu et al., 2016, 2019). This chapter addresses this gap, by investigating the Chinese luxury market and the way Chinese consumers utilise, interact, and perceive mass-market digital strategies. As such, we draw on findings from Liu et al. (2019), who explored the implications of digital marketing on WeChat within the Chinese luxury fashion market. This chapter seeks to provide thought provoking questions and future pathways for research into one of the most lucrative markets: the Chinese luxury industry.

\section{The Chinese luxury fashion industry, its consumers, and digital marketing}


As alluded to, the luxury fashion industry has changed in that it increasingly adapts to a consumer world that seeks $24 / 7$ access to information and fosters a 'see-now-buy-now' phenomenon (Newbery \& Haschka, 2018; Reuters, 2018). The latter emerged in 2016, when luxury fashion companies retaliated in order to avoid copies of their garments being sold on the high street prior to them being released in their own stores, which previously was within a 6-months timeframe. 'See-now-buy-now' implies that collections are sold simultaneously with being shown on the catwalks through s-commerce platforms (e.g. Instagram or Facebook in Western countries and WeChat and Weibo in China) (Fraser \& Dutta, 2008; Abnett, 2016; Lin et al., 2017; Bürklin et al., 2019). Key luxury fashion brands that have adopted the 'see-nowbuy-now' approach fully are Rebecca Minkoff, Massimo Dutti, and Mulberry, whilst Louis Vuitton, Prada, and Jil Sander have seen a partial adoption through capsule collections or limited items (Newbery \& Haschka, 2018). Whether or not 'see-now-buy-now' is a short term trend or here to stay is out of the scope of this chapter, yet what can be said is that it has changed the way consumers engage with (luxury) fashion organisations and the way they gain information and make purchases. This highlights how important digital strategies are for luxury fashion organisations, as these (digital platforms) allow luxury fashion organisations to have a real time interaction with their consumer base and react to ever increasing consumer demands. Digital platforms, which here include social media, are global in nature and as such have made it possible to reach a global audience instantaneously and in real time (Blazquez et al., 2019; Henninger et al., 2019).

A further change that can be observed is the way luxury fashion organisations are communicating with their customers, who currently predominantly fall within Generation $Y$ or the Millennial Generation and as such are aged between 23 and 38 (Lannes, 2019). Millennials have been strongly affected by China's 'one-child policy', which was introduced in 1979, as a measure to control how many children are born in China, as the government had ambiguous economic growth plans, which would have been impacted by a domestic population number, which in the late 1970s approached 1billion (BBC, 2015). A consequence of this policy was that a vast majority of individuals born between 1979 and 1996 do not have any siblings and thus, they have their parent's full attention and spending power, which can be diverted towards luxury products (BBC, 2015; Lannes, 2019). It is a generation that has first-hand experience with the technological (r)evolution through the introduction of the internet, smart phones, and real time information. They are described as self-confident with a strong tendency to show high individuality, they are computer savvy, and quite openly admitting to increasingly purchase luxury products to not only show off their success, but also treat themselves (Valentine \& Powers, 2013; Rogers, 2013; Deloitte, 2017; Liu et al., 2016, 2019; McKinsey, 2019). The former might seem contradicting, as the Chinese market has predominantly been associated with collectivism and, in a way, uniformity, yet the introduction of the 'one-child policy' has "resulted in a dramatic cultural and societal shift in Chinese society" (Chen, 2015: 167), which can be challenging for companies, including luxury fashion providers (Kang, 2017; Cai et al., 2018). Generation $Y$ is different to any previous ones in that they are more educated, with $25 \%$ holding a bachelor's degree or higher, and approximately $66 \%$ are passport holders, and thus have had exposure to different countries, lifestyles, cultures (Kidwai, 2019; McKinsey, 2019). Generation $Y$ furthermore had more opportunities, with being able to not only travel outside the country, but also study aboard (McKinsey, 2019), thereby gaining more exposure to pop culture and different luxury brands.

Yet millennials are not the only luxury spending power, their successors, Generation $Z$, born between 1997-2015, are increasingly becoming the centre of attention of luxury fashion brands, as they make up 20\% of the Chinese population (Reuters, 2019; Twigg, 2019). Contrary to the millennials, Generation Z are often described as digital natives, as such they have grown up with technological innovations that they see as a normality rather than 'lifechanging' (Twigg, 2019). The Chinese Generation Z also differs from their counterparts in other 
countries in that they account for $13 \%$ of the household spending in their own country, which is significantly lager and remarkable (McKinsey, 2019). Moreover, unlike the Western Generation Z, which has experienced the economic crisis in 2008, the Chinese Generation Z has benefitted from a prospering economy, which has resulted in different attitudes towards 'luxury'. Whilst the Western Generation Z often looks for experiences over materialistic items, the Chinese Generation $Z$ enjoys spending money on luxury goods (Athwal et al., 2019; Bloomberg, 2019; Yao et al., 2019). Interestingly, the Chinese Generation Z has developed a lot more patriotism when it comes to fashion, comparatively to previous generations. Various luxury fashion brands including Dolce \& Gabbana, Dior, and Balenciaga have suffered in the Chinese market after committing cultural faux pas, which resulted in a negative social media storm (Galvan, 2018; Handley, 2019). In line with this there is also a growing trend of Chinese Generation Z consumers to "now bypassing brands that focus much of their marketing on their illustrious European or American heritage and are looking for Made in China products instead" (Twigg, 2019).

As such it may not be surprising that past research found a shift in Chinese consumer (Generation Z) attitudes to become increasingly similar to traits mainly associated with individualistic cultures, and may include, but are not limited to materialism, self-reliance, hard working, and open and frankness in working relationships (e.g. Peppas \& Yu, 2004). These attitude shifts may be responsible for an emerging change in consumer patterns from previously making involvement purchases, which implies careful research and a well informed decision-making process, to increasingly making impulsive decisions, which means that consumers see, for example a luxury bag, and buy it without looking at any other sources for information about the brand or product itself (Zhang, 2017; White \& Denis, 2019). To reiterate this further, whilst in 2010 only one in four luxury purchasing decisions were made in one day (impulsive), this has shifted to one in two by 2017 (Bu et al., 2017). In the Western hemisphere individuality is nothing new, yet it takes some getting used to in the Chinese context. Within Western countries it is not uncommon for consumers to seek active dialogues with companies, whereby they can not only read information about new product launches, but also write reviews, post blogs, and hold a dialogic communication. Yet, within China these aspects are new and noteworthy and have only more recently emerged (Kim et al., 2019). A question that could be raised here is whether this shift in Chinese consumer behaviour is related to becoming more individualistic or whether it is simply a result of the increased use of technology and more specifically social media. As will be highlighted in the following social media has developed differently in China compared to the Western world, combined with different economic prerequisites (boom versus crisis) and attitudes towards luxury spending, it may not be surprising that their purchase behaviour may change. Having said that key motivators for Chinese luxury consumers to purchase luxury fashion remain: 1) the ability to show off wealth, which links to seeking prestige and recognition; 2) showing social belonging (bandwagon effect), and 3) hedonic values (emotional value/attachment) (Vingeron \& Johnson, 1999; Deloitte, 2017; Henninger et al., 2017; McKinsey, 2019).

For luxury fashion companies it is vital to react to these changes, seeing as Chinese consumers are ever increasingly dominating the luxury market: in 2008 they accounted for only $12 \%$ of the global luxury spending, which has increased to $75 \%$ in 2016 (Bu et al., 2017), as such they provide an interesting context for further investigations. A key question that emerges here however is whether the thirst for individuality is reflected in the way Chinese luxury consumers, especially Generation Z, want to receive information from these luxury fashion brands. Does this societal shift in attitude imply messages need to be delivered in an even more personalised manner, and thus moving away from mass-media platforms? To be even more drastic, would this mean that using social media platforms could be damaging to luxury fashion brands in their attempt to growing a lucrative market? These questions are further explored in the following. 
In today's (Western) world companies can no longer hide as information is broadcasted in real time to a global audience (e.g. Doherty \& Delener 2001; Kaplan \& Haenlein, 2010). Thus, our world becomes increasingly transparent and consumers more and more knowledgeable, which can have both negative and positive consequence. An example of the former is an incident that highlighted "destroying unsold clothes is fashion's dirty secret. And we're complicit" (Siegel, 2018), which has had negative consequences on the fashion retailers involved with consumers voicing their opinions and demanding changes in the companies' behaviour. On the other hand, the news that "Prada announces it is to go fur-free" (Bramley, 2019) has had a positive impact and received popularity especially amongst consumers that have animal rights at heart. One aspect that the reader needs to keep in mind here is that Western and Chinese media have developed very differently. Whilst in the Western world media has enjoyed freedom of speech and access to quite literally any digital channel available on the market, the Chinese media has had stronger government regulations. The enforcement of tight government regulations, especially on social media, is one of the reasons, why for example Western social networking platforms such as Instagram, Twitter, and Facebook, either cannot at all be used and/or visited when in Mainland China (Xu, 2104) or with extreme difficulty. The only ways to make use of Western platforms are either through virtual private networks (VPNs), proxy servers, or micro-blogging platforms, such as Weibo (Shambaugh, 2016). As such, Chinese netizens have found ways to "voice opinions or discuss taboo subjects" and engage with Western platforms (Shambaugh, 2016: 293). Yet, having to go through these hurdles implies that Chinese consumers may not be able to catch up on all the news and happenings, seeing as VPNs and proxy serves can fail and may potentially not allow netizens to access these platforms for days. Thus, there was a need to provide platforms that overcome these challenges in order to engage with Chinese consumers in a more convenient manner, which is discussed in the following.

Although media censorship may not necessarily be seen as something positive, in this case it has led to enhanced creativity and innovation, with the creation of one of the most influential Chinese micro-blogs - (Sina) Weibo (新浪微博) - which has an average daily user rate of 374.1 million in 2019 and is expected to grow by approximately $12 \%$ and thus reach 418.4 daily users in 2021 (Statista, 2019). Yeo and Li (2012) describe the Chinese internet as "one of the most vibrant economic and social cyberspaces in the world. (...) Entrepreneurial companies have created tens of billions of dollars in economic value" (p. 7). This further highlights that 'digital' has not only developed differently in China, but it plays a vital role. A further innovative creation that is commonly used within the Chinese market is WeChat. WeChat is not only used by billions of people in China, but has also emerged as 'the' app, which implies that it is used on an everyday basis in China (Deng \& Chen, 2018; Kharpal, 2019). A key question that emerges here is what makes WeChat so special? The answer is that WeChat is a multi-purpose platform that combines features from a variety of popular Western apps, such as the What'sApps messaging services that allows individuals to stay connected, Twitter's newsfeed to keep up-to-date with what is going on in people's lives, but also with product launches and sales, Facebook's memory sharing, and Instagram's picture posting. What makes WeChat the most popular daily app however is the fact 1) you can scan QR codes to be added into different groups and find out more about brands and their offerings, and 2) it has mobile payments incorporated, as such individuals can transfer money to one another by either sanding it to existing contacts, or scanning unique QR codes (Atkinson, 2018). As such, it is a one-stop-shop that allows for easy access to information and an opportunity to purchase products on the go, securely through the incorporated payment function. Seeing how media has been created and the functions of these platforms, it could be suggested that Chinese consumers are inclined to receive content that is intended for the mass-market. 
Scanning QR codes to receive information implies that the content is predetermined and not necessarily customised to the individual.

The newest social media trends utilised especially by Generation Z are Little Red Book (小红书) and TikTok (抖音). Little Red Book or RED can be described as a mixture of Instagram and Amazon. The luxury e-commerce platform is content driven, which implies that it relies on customer reviews as well as Key Opinion Leaders (KOLs), who share their experiences of luxury products with a global audience. The app has managed to attract the most 'it' influencers to their platform, who regularly share their shopping experiences, hobbies, and lifestyle tips, thereby reaching approximately 200million users daily (Achim, 2019; Fannin, 2019). The importance of engaging with KOLs is further addressed in a later section of this chapter. The New York Times states that TikTok "will change the way your social media works - even if you're avoiding it" (Herrman, 2019), it is a video app that encourages responding to previously posted content and connect with other users, whilst at the same time utilises \#hashtags and creates challenges that users can get involved with. As such, the app is highly interactive and reaches a younger generation, with luxury brands, such as Burberry and Calvin Klein testing its potential (Lieber, 2019).

Lannes (2019) indicates that the Chinese luxury consumer market sales is growing at an average rate of $20 \%$, with one of the key contributing factors being digitalization, linked to the previously mentioned innovations that allow Chinese consumers to gain information at their fingertips. Generally speaking there are four main channels that are used by (fashion) luxury retailers within China to broadcast their newest product launches, sales events, or sponsored content that features key opinion leaders:

1) Brand owned:

As implied by the name, these are owned by the individual luxury fashion brands, for example LouisVuitton.cn or cn.Burberry.com. A key advantage here is the fact that the content covered on the platforms, whether this be the company website or official social media channel, is controlled by the organisations, and thus, they can ensure that the content 'fits' their image and intended consumer experience. The design and feel of the brand is directly reflected in these outlets, as the brand has ultimate control. A further benefit is the fact that brands are able to charge full prices on their products (Blazquez, 2014; Baetzgen \& Tropp, 2015; Lannes, 2019). The only drawback that can be mentioned here is potential 'footfall' or traffic of these accounts, as consumers have to actively choose to go to the brand's information channels and explore them. As such, it is unlikely that they would 'accidently' attract individuals to look at their newest posts, but rather centre on their core customer base.

2) Co-operators:

This implies that luxury fashion products are advertised through channels that receive high traffic through daily users. In China for example, Tmall, a business-to-consumer platform, is a key online retailer that allows, in this case, luxury fashion retailers to sell their goods to consumers in China, via a local, trusted, online Tmall flagship store. A key feature on the Tmall site is the AliWangWang ( 阿里旺旺) chat, which allows consumers to engage with the sellers and/or their respective customer service teams, thereby creating strong customer relationships. Although fashion luxury brands do not have full control over these channels (Tmall flagship stores), the overall control remains high, with the added benefit of profiting from the daily user traffic to Tmall (Tmall, 2015; AIO, 2019; Lannes, 2019). Similar to Tmall, WeChat commerce is often used as a co-operator channel to broadcast and boost luxury fashion sales. Seeing as Chinese consumers use WeChat on a daily basis, it is highly likely that they may browse different notifications, scan QR codes, and gain friend recommendations for 
blogs, posts, and related brand content. As such luxury fashion brands may experience an increased interest in their products/content as consumers almost 'stumble' across content and information by browsing on these two different platforms. Yet, luxury retailers need to keep in mind that giving more power to third party platforms can also create challenges, in that there may be inconsistencies in terms of how merchandise is presented. This in turns can lead to confusion and potential mistrust of authenticity of products (Liu et al., 2019). As indicate din the introduction, whilst it is important to develop an omni-channel strategy (Blazquez, 2014; Kent et al., 2016), this needs to be carefully done in order to ensure that the brand experience remains the same.

\section{3) Aggregators:}

Working with aggregators implies that, in this case, luxury fashion brands are outsourcing the responsibility of developing and continuously growing high-traffic channels to a third party (the aggregators). Examples of successful aggregators in China are JD.com's Toplife and TMall's Luxury Pavilion. In an interview with Style Tmall's Fashion and Luxury president Jessica Liu highlights that the Luxury Pavilion "was aimed at helping luxury brands gain insight into their clients and provide them with the exact products they desire" (Chen, 2018a). Aggregator sites such as JD.com Toplife and Tmall Luxury Pavilion collect data on their users through cookies and as such, are aware of what these consumers look at, what they purchase, how often they visit the site, and what lifestyle they prefer. This information can be provide vital insights into the Chinese millennial luxury consumers, who are increasingly exposed to Western culture and enjoy more freedom to travel and access to education both at home and abroad. In order to align with the luxury brand feel and to comply with the information gathered whilst these Chinese millennial consumers browse these e-commerce platforms (Tmall Luxury Pavilion and Toplife), both JD.com Toplife and Tmall Luxury Pavilion have invested in new technologies, such as augmented reality (AR) and virtual reality (VR) to further promote omni-channel sales (Blazquez, 2014). Interestingly, Tmall Luxury Pavilion has recently created a new feature in its app entitled 'Maison', which allows luxury fashion brands to "customize their digital editorial content and storefront design to speak to their brand image and tone of voice, as well as offer early access to Alibaba's latest technology, such as 3D popup shops" (Chou, 2018). This feature is especially attractive to the Chinese luxury fashion consumer market, which is dominated by tech savvy millennials that rely on social media for information and want to have a unique customer experience (Chen, 2015; Lannes, 2019)

4) Luxury vertical sites:

These third party sites offer selected lines and product ranges at a heavily discounted price, in the Western world one of the most prominent sites is YOOX, whilst in China Mei.com or Secoo might be more popular. Although these websites currently remain popular, it is questionable whether this will be the case in the future, as there seems to be a shift in consumer behaviour that has been observed since 2015 in that luxury fashion brands and reseller platforms move away from simply recruiting customers to retaining them. With Chinese customers striving for individuality and wanting to showcase their ability to purchase luxury items, we might see a move away from 'bargain sites' in the future (Jing Daily, 2014; Arcibal, 2019; Lannes, 2019).

Although these four different channel types are vital in terms of broadcasting messages and providing consumers with the opportunity to purchase these goods they are not the only ones consumers utilise to gain information. As alluded to, Chinese luxury fashion consumers actively look for information, both online and offline, whilst the four channels previous discussed may play a key role, they further consult none brand official accounts and sites on Weibo, WeChat, RED and TikTok, for information. Chinese consumers spend on 
average from 3 to 5 hours on social media and other platforms to gain the newest information about their favourite luxury fashion brands (McKinsey, 2019). This indicates that collaborating with key opinion leaders may no longer be an option, but rather an essential for luxury fashion brands. The brand related content may be written by famous luxury fashion bloggers, such as Mr Bags, Becky Li, Chrison, Dipsy, Fil Xiaobai and/or other influencers (Yang, 2018). Previous studies (Blazquez, 2014; Blazquez Cano et al., 2019; Siddiqui et al., 2019; Vazquez et al., 2019) indicate that these opinion leaders play a vital role within purchase decision-making, as well as creating trust between the consumer and the luxury fashion brands. On average, posts by key opinion leaders receive four times more views than content posted by official brand accounts, a reason for this could be that these key opinion leaders are seen as 'friends', everyday people, who have managed to gain a high following, yet remain the person from next door (Flora, 2017; Chen, 2018b; Liu et al. 2019). They (KOLs) are able to create high engagement with their followers and influence on their buying decisions (Ding et al., 2019), which can be evidenced seeing as Mr Bag's collection designed for Tod's sold out within one hour of it being released (Yang, 2018), whilst Becky Li's collection in collaboration with Rebecca Minkoff sold out completely in two days (Chen, 2018b). An explanation that can be given is highlighted in an interview with Style, whereby Becky Li insisted "the new generation of consumers are savvier and more rational. Instead of chasing blindly after the latest trends, they are more focused on their own needs" (Chen, 2018b) and expressing themselves as individuals. This links back to what has previously been described as the 'bandwagon effect' in that consumers seek to be part of an 'in' group and be associated with the KOLs they follow and idolise (Vingeron \& Johnson, 1999; Deloitte, 2017; Henninger et al., 2017; McKinsey, 2019). From the interview with Becky Li (cited in Chen, 2018b) it becomes apparent that the 'new' luxury consumers seek more of an experience rather than product quality. They further want information from multiple sources, whether or not this information is necessarily customised is only a secondary aspect, as long as the overarching message is coherent and consistent across the platforms, engagement is high (Balzquez, 2014; Chen, 2018b). This follows in line with Liu et al. (2019) finings in that social media content can not only create a buzz around certain topics, but also is effective electronic word-of-mouth (eWOM). Liu et al. (2019) insist that in China Generation $Y$ and more so Generation $Z$ follow their peers' advice and guidance. Peers in this case also incorporate KOLs, who regularly post their opinions on a variety of platforms. A question that has been raised previously concerns luxury fashion brands and social media and whether a 'mass market' strategy is the right way forward for these luxury fashion brands. Drawing on Kapferer's (2000) brand identity prism consisting of physique (product), relationship (brand - consumer), reflection, personality, culture, and selfimage, it becomes apparent that social media enhances each of the aspects, especially the 'new generation' platforms, such as RED and TikTok, as they are honing in on culture, personality, and the relationship aspect. As such, it could be suggested that successfully integrating new technologies can enhance a luxury brand's identity and image, especially in China, thus, would be a positive move forward.

Although the Chinese market and more specifically Chinese luxury fashion consumers are tech savvy and enjoy searching for information online, luxury fashion companies are fazed by an idiosyncrasy. To explain, to date only $8 \%$ of luxury fashion purchases are made online, with the remaining $92 \%$ being made in traditional bricks and mortar stores. This may come as a big surprise, seeing as China is not only highly connected in terms of internet usage, but also, as previously mentioned, has developed some of the most innovative Apps, such as WeChat (McKinsey, 2019). So what does this mean? Is all the digitalization and investments made in digital strategies a waste of time? On the contrary, according to Liu et al. (2019) digital strategies in the Chinese market are more important than ever before. They denote that their findings contrast what has previously been sated in the literature, in that it is vital to have a digital footprint, spread across multiple platforms, yet the overall brand message needs to be 
coherent and consistent. This however, may at times be challenging, as was pointed out in the section on 'co-operator channel', where luxury fashion brands may loose some of their control and ability to portray their brand image and actual feel of the brand in a manner that matches their brand-owned channels. One way to overcome these challenges is to invest more in aggregator channel collaborations, such as Tmall Luxury Pavilion's Maison store, which allows for high customisation and provides a feel of 'exclusivity and luxury'. Yet, simply posting content is no longer enough for a demanding, tech savvy customer base, creativity and innovation are key (Liu et al., 2016, 2019), which is why a majority of luxury brands decide to collaborate with key opinion leaders. A conclusion that can be drawn here is that the product or the brand in itself may become les and less important. Whether someone buys a Louis Vuitton bag, a Prada purse, or a Coco Channel clutch is no longer the key focus, but rather it is the brand experience that ideally is created through the omni-channel (cross-channel) integration (Bu et al., 2017; Liu et al., 2019). As such, brand pre-eminence moves up high on the priority list, which here implies these are well known luxury fashion brands that manage to satisfy a high level of customer experience and manage to coherently broadcast their message across all channels, whether they are brand-owned or part of a collaboration, or discussed as part of brand related content by key opinion leaders.

Liu et al. (2019) further highlighted in their paper that various of the luxury brands that participated in their study have managed to strike a balance between their online and offline (omni-channel) strategy of consumer retention and acquisition, in that they have utilised WeChat as a medium. As previously indicated WeChat is not simply an app, but rather the app that is used on a daily basis as a method of payment and source of information that has the power to guide consumers/users towards new products. Various luxury fashion companies have already incorporated training sessions on this communication channel, as such it is further proposed that more investment is made into new technologies, such as RED and TikTok, in order to ensure that brands are not missing out on opportunities to target an emerging market segment - Generation Z.

\section{Conclusion}

Whilst R.E.M where right in denoting 'it is the end of the world as we know it' they conclude 'I feel fine'. Technology and digital innovations are increasing and the creation of new platforms will continue to grow and with it the need to explore their potential. Although it may be quite obvious from industry reports that digital communication channels have developed differently within Western countries and China due to tight government regulations this is not always reflected in academic literature. Liu et al. (2019) were among the first authors to explicitly state that there is a need for luxury fashion companies to provide their staff with training opportunities on Chinese social media, as well as decentralizing digital marketing strategies from European headquarters. They recognised that the societal shift that was partially influenced by the 'one-child policy' has not only created different attitudes towards luxury, but also differs dramatically from their Western counterparts.

To the question of whether mass-market digital strategies work in the Chinese market the question remains partially unanswered. From company reports and news articles it is apparent that Chinese luxury consumers, who fall within the millennial generation, actively seek information from a variety of sources. They enjoy creative content and longing to gain information. WeChat allows easy access to brand news, by simply scanning QR codes, as such it could be insinuated that yes, these mass-market strategies work in the Chinese market. Yet, this cannot be confirmed until more research focuses on this area.

A suggestion for future research to investigate the consumer decision-making model, specifically comparing and contrasting Generations $Y$ and $Z$, within the context of luxury fashion and China. Our chapter alludes to the fact that there is a difference not only within these generations, but also in the way they source and act upon information. 


\section{References}

Abnett, K. (2016) Are See Now, Buy Now Shows Driving Sales, Business of Fashion (Online): https://www.businessoffashion.com/articles/intelligence/are-see-now-buy-nowshows-driving-sales, 27/09/2019

Achim, A.L. (2019) The growing influence of Little Red Book, Jing Daily (online): https://jingdaily.com/the-growing-influence-of-little-red-book/, 17/10/2019

AIO (2019) What is AliWangWang?, AIO (online): https://en.aioexpress.com/news6101, $05 / 10 / 2019$

Arcibal, C. (2019) Forget the overseas holiday, Chinese consumers will soon shop at home for half of all luxury goods they buy, says HSBC, South China Morning Post (online): https://www.scmp.com/business/china-business/article/3004686/forget-overseasholiday-chinese-consumers-will-soon-shop, 05/10/2019

Atkinson, S. (2018) WeChat hits one billion monthly users- are you one of them?, BBC (online): https://www.bbc.co.uk/news/business-43283690, 02/10/2019

Athwal, N., Wells, V., Carrigan, M., and Henninger, C.E. (2019) Sustainable luxury marketing: a synthesis and research agenda - International Journal of Management Review, 21(4): 405-426

Baetzgen, A., \& Tropp, J. (2015) How can brand-owned media be managed? Exploring the managerial success factors of the new interrelation between brands and media, International Journal on Media Management, 17(3): 135-155.

BBC (2015) Explainer: What was China's one-child policy?, BBC (online): https://www.bbc.co.uk/news/world-asia-china-34667551, 27/09/2019

Blazquez, M. (2014) Fashion shopping in multichannel retail: the role of technology in enhancing the customer experience. International Journal of Electronic Commerce, 18(4): 97-116

Blazquez, M., Zhang, T., Boardman, R, \& Henninger, C.E. (2019) Exploring effects of social commerce on consumers' browsing motivations and purchase intentions in the UK fashion industry, (Chapter 6): 99-115, in Boardman, R., Blazquez Cano, M., Henninger C.E., \& Ryding, D. (eds) Social Commerce: Consumer Behaviour in Online Environments, Palgrave: London

Bloomberg (2019) China's generation $Z$ teens spend more and worry less than you do, Bloomberg News (online): https://www.bloomberg.com/news/articles/2019-0123/china-s-gen-z-teenagers-spend-more-and-worry-less-than-you-do, 17/10/2019

Bramley, E.V. (2019) Prada announces it is to go fur-free, The Guardian (online): https://www.theguardian.com/fashion/2019/may/23/prada-announces-it-is-to-go-furfree, 05/10/2019

Bu, L., Durand-Servoingt, B., Kim, A., \& Yamakawa, N. (2017) More global, more demanding, still spending, McKinsey (online): https://www.mckinsey.com/businessfunctions/marketing-and-sales/our-insights/chinese-luxury-consumers-more-globalmore-demanding-still-spending, 27/09/2019

Bürklin, N., Henninger, C.E., \& Boardman, R. (2019) The historical development of social commerce, (Chapter 1): 1-16, in Boardman, R., Blazquez Cano, M., Henninger C.E., \& Ryding, D. (eds) Social Commerce: Consumer Behaviour in Online Environments, Palgrave: London

Cai, H., Zou, X., Feng, Y., Liu, Y., and Jing, Y. (2018) Increased need for uniqueness in contemporary China: empirical evidence, Frontiers of Psychology, 9:554

Chen, R. (2015) Weaving individualism into collectivism: Chinese adults' evolving relationship and family values, Journal of Comparative Family Studies, 46(2), 167-179

Chen, V. (2018a) Are Chinese e-commerce platforms ready for a luxury update?, Style (online) https://www.scmp.com/magazines/style/news-trends/article/2149449/are-chinese-ecommerce-platforms-ready-luxury-update, 05/10/2019 
Chen, V. (2018b) Meet Becky Li, China's digital influencer who sold 100 Mini Coopers in five minutes, Style (online): https://www.scmp.com/magazines/style/peopleevents/article/2144489/meet-becky-li-chinas-digital-influencer-who-sold-100, $06 / 10 / 2019$

Chou, C. (2018) Tmall Luxury Pavilion gets 'Maison' upgrade, Bottega Veneta latest to join, Alizila (online): https://www.alizila.com/tmall-luxury-pavilion-gets-maison-upgrade/, 05/10/2019

Deloitte (2017) Bling it on - What makes a millennial spend more?, Deloitte (online): http://info.deloitte.no/rs/777-LHW-455/images/Bling-it-on.pdf, 17/10/2019

Deloitte (2019) Global powers of luxury goods 2019: bridging the gap between the old and the new, Deloitte (online):

https://www2.deloitte.com/content/dam/Deloitte/ar/Documents/Consumer and Ind ustrial Products/Global-Powers-of-Luxury-Goods-abril-2019.pdf, 27/09/2019

Deng, I., \& Cheng, C. (2018) How WeChat became China's everyday mobile app, South China Morning Post (online): https://www.scmp.com/tech/article/2159831/how-wechatbecame-chinas-everyday-mobile-app, 05/10/2019

Ding, W., Henninger, C.E., Blazquez Cano, M., and Boardman, R. (2019) Effects of beauty vloggers' eWOM and sponsored advertising on Weibo, Chapter 13: 235-254, in Boardman, R., Blazquez-Cano, M., Henninger C.E., \& Ryding, D. (eds) Social Commerce: Consumer Behaviour in Online Environments, Palgrave: London.

Doherty, N., \& Delener, N. (2001) Chaos theory: marketing \& management implications, Journal of Marketing Theory and Practice, 9(4), 66-75.

Fannin, R. (2019) Why email and cash are dead in China, Forbes (online): https://www.forbes.com/sites/rebeccafannin/2019/08/18/why-email-and-cash-aredead-in-china/, 17/11/2019

Flora, L. (2017) Interview: Chinese KOL Becky Li on WeChat and China's Influencer Economy, Daily Insights (online): https://www.l2inc.com/daily-insights/interview-chinese-kolbecky-li-on-wechat-and-chinas-influencer-economy, 06/10/2019

Fraser, M., \& Dutta, S. (2008). Throwing Sheep in the boardroom: How online Social networking Will Transform Your Life, Work and World, Wiley \& Sons: Hoboken, NJ

Galvan, B. (2019) Not just Dolce \& Gabbana: five other brands that riled Chinese with fashion and beauty faux pas, South China Morning Post (online): https://www.scmp.com/lifestyle/fashion-beauty/article/2174666/not-just-dolcegabbana-five-other-brands-riled-chinese, 17/10/2019

Handley, L. (2019) Luxury brands must now show they are 'good Chinese citizens' after T-shirt territory anger, experts say, CNBC (online): https://www.cnbc.com/2019/08/19/whatluxury-fashion-brands-must-now-do-after-china-t-shirt-anger.html, 17/10/2019

Henninger, C.E.*, Alevizou, P.J., Tan, J., Huang, Q., \& Ryding, D. (2017) Consumption strategies and motivations of Chinese consumers - the case of UK sustainable luxury fashion. Journal of Fashion Marketing \& Management, 21(3): 419-434

Henninger, C.E., Bürklin, N., \& Parker, C.J. (2019) Social media's evolution in s-commerce, (Chapter 2): 17-42, in Boardman, R., Blazquez Cano, M., Henninger C.E., \& Ryding, D. (eds) Social Commerce: Consumer Behaviour in Online Environments, Palgrave: London

Herrman, J. (2019) How TikTok is rewriting the world, NY Times (online): https://www.nytimes.com/2019/03/10/style/what-is-tik-tok.html, 17/10/2019

Jing Daily (2014) China's luxury consumers buy for quality while Americans seek bargains, Jing Daily (online): https://jingdaily.com/chinas-luxury-consumers-buy-for-quality-whileamericans-seek-bargains/, 05/10/2019

Kaplan, A.M., \& Haenlein, M. (2010) Users of the world unite! The challenges and opportunities of social media, Business Horizon, 53, 59-68. 
Kang, S.C. (2017) Why Chinese consumers' growing individualism is a challenge, Jing Daily (online): $\quad$ https://jingdaily.com/consumer-loyalty-growing-individualism-posechallenges-brand-summit-china/, 05/10/2019

Kapferer, J.N. (2000) Strategic Brand Management - Creating and Sustaining Brand Equity Long Term, Kogan Page Publishers, 1st Edition

Kent, A., Vianello, M., Blazquez Cano, M., \& Helberger, E. (2016) Omnichannel fashion retail and channel integration: The case of department stored, Chapter 16: 398-419, in Vecchi, A., \& Buckley, C. (eds) Handbook of Research on Global Fashion Management and Merchandising, IGI Global: Hershey, PA.

Kharpal, A. (2019) Everything you need to know about WeChat - China's billion-user messaging app, CNBC (online): https://www.cnbc.com/2019/02/04/what-is-wechatchina-biggest-messaging-app.html, 05/10/2019

Kidway, F. (2019) Millennials: China's new economic force, China Daily (online): http://www.chinadaily.com.cn/a/201901/16/WS5c3ea92ba3106c65c34e4ca5.html, 17/10/2019.

Kim, A., Luan, L., \& Zisper, D. (2019) The Chinese luxury consumer, McKinsey (online): https://www.mckinsey.com/featured-insights/china/the-chinese-luxury-consumer, 05/10/2019

Lannes, B. (2019) What's powering China's market for luxury goods?, Bain \& Company (online): https://www.bain.com/insights/whats-powering-chinas-market-for-luxury-goods/, 27/09/2019

Lee, D., Moon, J., Kim, Y.J., \& Mun, Y.Y. (2015) Antecedents and consequences of mobile phone usability: linking simplicity and interactivity to satisfaction, trust, and brand loyalty, Information \& Management, 52: 295-304

Lieber, C. (2019) Gen Z loves TikTok. Can fashion brands learn to love it too?, Business of Fashion (online): https://www.businessoffashion.com/articles/professional/gen-zloves-tiktok-can-fashion-brands-learn-to-love-it-too, 17/10/2019

Lin, X., Li, Y., \& Wang, X. (2017) Social commerce research: definition, research themes and the trends. International Journal of Information Management, 37, 190-121

Liu, S., Perry, P., \& Gadzinski, G. (2019) The implications of digital marketing on WeChat for Luxury fashion brands, Journal of Brand Management, 26: 395-409

Liu, S., P. Perry, C. Moore, and G. Warnaby. 2016. The standardization-localization dilemma of brand communications for luxury fashion retailers' internationalization into China. Journal of Business Research, 69 (1): 357-364.

McCormick, H., Cartwright, J., Perry, P., Barnes, L., Lynch, S., \& Ball, G. (2014) Fashion retailing - past, present and future, Textile Progress, 46(3): 227-421

McKinsey (2019) China Luxury Report 2019, McKinsey (online): https://www.mckinsey.com/ /media/mckinsey/featured\%20insights/china/how\%20y oung\%20chinese\%20consumers\%20are\%20reshaping\%20global\%20luxury/mckinsey -china-luxury-report-2019-how-young-chinese-consumers-are-reshaping-globalluxury.ashx, 05/10/2019

Morgan-Thomas, A., \& Veloutsou, C. (2015) Beyond technology acceptance: Brand relationships and online brand experience. Journal of Business Research, 66(1): 21-27.

Newbery, M., \& Haschka, Y. (2018) What 'see now, buy now' means for fashion supply chain, Just Style (online): https://www.just-style.com/analysis/what-see-now-buy-nowmeans-for-the-fashion-supply-chain id134666.aspx, 16/10/2019.

Rogers, G. (2013) The rise of Generation Y in the sustainable marketplace, The Guardian (online): http://www.theguardian.com/sustainable-business/blog/rise-generation-ysustainable-marketplace, 15/09/2019 
Reuters (2018) Fashion Brands slow to see now, buy now, Business of Fashion (online): https://www.businessoffashion.com/articles/news-analysis/fashion-labels-dither-oversee-now-buy-now, 16/10/2019.

Reuters (2019) China's Gen-Z shoppers fuelling luxury market momentum, Business of Fashion (online): https://www.businessoffashion.com/articles/news-analysis/chinas-gen-zshoppers-fuelling-luxury-market-momentum, 17/10/2019

Shambaugh, D. (2016) The China Reader: rising power, $6^{\text {th }}$ edition, Oxford University Press: Oxford

Siddiqui, N., Mannion, M., \& Marciniak, R. (2019) An exploratory investigation into the consumer use of WeChat to engage with luxury fashion brands (Chapter 12): 213-234, in Boardman, R., Blazquez-Cano, M., Henninger C.E., \& Ryding, D. (eds) Social Commerce: Consumer Behaviour in Online Environments, Palgrave: London.

Siegel, L. (2018) Destroying unsold clothes is fashion's dirty secret. And we're complicit., Huffington Post (online): https://www.huffingtonpost.co.uk/entry/burberry-burnclothes-fashion-industry-

waste us 5bad1ef2e4b09d41eb9f7bb0?ri18n=true\&guce referrer=aHROcHM6Ly93 d3cuZ29vZ2xILmNvbS8\&guce referrer sig=AQAAAIf4ZJ3JGHfWyFVzGIO2hlxBlpNr QUOBpkXflfoE2d305anqMXNBoyrhTK1VZP PAeOKh9VGR7Z3SjcNDFyblztmt0OSARmYUjrv2 iDRSvN3Sh1g9KOujmnXU9BXKm6W Vv8vaAiZSSBqzlck8jmirBy5WOhv7tVAl1uh Wm7\&guccounter $=2,27 / 09 / 2019$

Statista (2019) Number of Sina Weibo users in China from 2017 to 2021 (in millions), Statista (online): $\quad$ https://www.statista.com/statistics/941456/china-number-of-sina-weibousers/, 05/10/2019

Tmall (2015) Welcome to Tmall, Tmall (online): https://about.tmall.com/tmallglobal/opening a store, 05/10/2019

Valentine, D.B. \& Powers, T.L. (2013) Generation Y values and lifestyle segments, Journal of Consumer Marketing, 30(7): 597-606

Vazquez, D., Cheung, J., \& Wu, X. (2019), Investigating Chinese audience-consumer responses towards TV character-based fashion related social media content, International Journal of Business \& Globalisation, 22(1): 53-73

Vingeron, F. \& Johnson, L.W. (1999) A review and a conceptual framework of prestige-seeking consumer behaviour, Academy of Marketing Science, 1: 1-15

White, S. \& Denis, P. (2019) China's 'Gen Z' shoppers fuelling luxury market momentum: Bain, Reuters (online): https://www.reuters.com/article/us-luxury-outlook-bain/chinas-genz-shoppers-fuelling-luxury-market-momentum-bain-idUSKCN1TE18B, 17/10/2019

$\mathrm{Xu}$, B. (2014) Media Censorship in China, Council on Foreign Relations (online): http://www.cfr.org/china/media-censorship-china/p11515, 27/09/2019

Yang, Q. (2018) Meet the Chinese influencers making waves in the fashion world, Vogue (online):

https://www.vogue.co.uk/article/chinese-influencers-to-know-now, 05/10/2019

Yao, Y., Boardman, R., \& Vazquez, D. (2019) Cultural Considerations in social commerce: the differences and potential opportunities in China, in Boardman, R., Blazquez-Cano, M., Henninger C.E., \& Ryding, D. (eds) Social Commerce: Consumer Behaviour in Online Environments, Palgrave: London.

Yeo, G., \& Li, E.X. (2012) Yin and Yang: Sina Weibo and the Chinese State, New Perspectives Quarterly, 29(2): 7-9

Zhang, M. (2017) Gen Z are driving China's consumer trend with impulse buying and instant gratification, South China Morning Post (online): 
https://www.scmp.com/business/china-business/article/2108141/gen-z-aredriving-chinas-consumer-trend-impulse-buying-and, 17/10/2019 